\title{
Arterial hypertension in children with Williams-Beuren
} syndrome

Received: 16 November, 2020

Accepted: 26 November, 2020

Published: 27 November, 2020

*Corresponding author: Loureiro Marília, Pediatric Cardiology Department, Centro Materno Infantil do Norte, Centro Hospitalar do Porto, Portugal,

E-mail:Imarilia.loureiro@gmail.com

https://www.peertechz.com

Check for updates

\author{
Novo Marta ${ }^{1}$, Loureiro Marília ${ }^{2 \star}$ and Rocha Liliana ${ }^{3}$ \\ ${ }^{1}$ Pediatric Department, Centro Hospitalar Universitário do Algarve, Unidade de Faro, Portugal \\ ${ }^{2}$ Pediatric Cardiology Department, Centro Materno Infantil do Norte, Centro Hospitalar do Porto \\ Portugal
}

${ }^{3}$ Pediatric Nephrology Unit, Pediatric Department, Centro Materno Infantil do Norte, Centro Hospitalar do Porto, Portugal
Williams-Beuren Syndrome (WBS) is a multisystemic disorder with prevalence of $1 / 7500$ [1], affects both genders equally and it is caused by a microdeletion of 26-28 genes, including elastin and NCF1 genes, of the chromosome region 7q11.23 [1,2]. The disease is transmitted in an autosomal dominant fashion, but almost all cases are the result of de novo mutations [1].

The main clinical features include: elfin facies (100\%), short stature, intellectual disability (75\%), cardiovascular $(80 \%)$ and genitourinary abnormalities and occasionally infantile hypercalcaemia $(15-45 \%)[1,3]$.

This article mainly focuses in cardiovascular manifestations, essentially hypertension, diagnoses approach and treatment. Supravalvular aortic stenosis (SVAS) is the most common cardiac alteration (35-65\%) [1], normally discreet or it can involve a long segment stenosis (15\%) [1]. SVAS can worsen with time, especially during the first 5years; in $30 \%$ of cases it might need cardiac surgery or catheterization with a mortal rate of $6 \%$ [4]. Branch or peripheral pulmonar artery stenosis $(60 \%)$ tend to improve or overcome spontaneously along time [1], essentially if occurs has a single event [4]. Supravalvar pulmonar stenosis is seen in approximately $10 \%$ of patients, demonstrating spontaneous improvement in many cases $[1,5]$. Other cardiovascular abnormalities are: stenosis of the thoracic or abdominal aorta, renal or intracranial arteries and/or vessels at other sites including the neck and limbs [1,7]. Septal defects, regurgitation or prolapse valve mitral, insufficiency or bicuspid aortic valve are seen in association with WBS. Children with WBS have higher risk of sudden death (1/1000 patients/ year) by ventricular hypertrophy (biventricular outflow tract obstruction), coronary anomalies (ostial or difuse stenosis or dilatation) and prolonged corrected QT (13\%) [1].

These patients are at high risk for systemic hypertension. Loss of function in the elastin gene is associated with increased intima-media thickness with thick irregular elastic fibres, swirling collagen and hypertrophied smooth muscle cells [2]. These vascular lesions are responsible for focal stenosis, generalized vascular narrowing and Hypertension (HTN) [3]. Vascular stiffness normally increases with ageing and comorbid conditions such as HTN and diabetes [3]. NCF1 is one of the deleted Williams genes, is a component of $\mathrm{NAD}(\mathrm{P}) \mathrm{H}$ oxidase complex and involved in generation of oxidase stress and reduced copy number of this gene are associated lower risk of HTN in WBS [6].

HTN occurs in about $50 \%$ of cases, at any age. Although in many patients it remains unexplained, most frequently found etiologies are: renal artery stenosis (50\%) and/or diffuse aortic narrowing and/or aortic coarctation and high sympathetic activity $[1,2]$.

Hypertension is also more common in subjects with a history of infantile hypercalcemia, even though it hasn't been found a correlation between them [2].

Severall genitourinary manifestations can occur in a SWB: multicystic kidney, renal hypoplasia or aplasia, ureterohydronephrosis and nephrocalcinosis (if hypercalcemia with hypercalciuria) [1]. It can cause hypertension and evolve to a renal chronic disease. 
Blood pressure measurement in both arms is recommended with use of a manual cuff at the end of the visit to minimize anxiety [3]. Consider cardiology or nephrology referral for hypertension when blood pressure is > 90th percentile for age and height [3], but HTN was defined blood pressure > 95th percentile for age and height. When these patients are diagnosed with hypertension, an investigation for vascular injuries passable of correction and evidence for end-organ damage should be performed [1]. Some experts, recommend an initial trial of antihypertensive medications and if HTN resists pharmacology therapy, it should proceed to investigate the renovascular causes [1,7]. However, other experts in the field would evaluate all patients with HTN for discrete vascular lesions that may be correctable and evidence for end-organ damage [1]. In HTN initial approach an abdominal ultrasound can be performed to mislead of genitourinary abnormalities and some serum blood (urea nitrogen, calcium, creatinine, 25hidroxyvitamin, 1,25-hydroxyvitamin and parathyroid hormone concentrations) and urinary tests (spot calcium/ creatinine ratio). Renal ultrasound with doppler flow studies of renal arteries and abdominal aorta is performed because of the increased likelihood that renal artery stenosis is the etiology of HTN [1]. Patients with highly suspicion and/or inconclusive studies and/or refractories to antihypertensive therapy can perform a computed tomography or magnetic resonance angiography and/or arteriography to identify the renovascular cause [1]. The choice of study should be based on individual patient's characteristics including the need for/ risk of sedation for the procedure, baseline renal function and clinical experience [1].

In patients whose initial work-up is negative or inconclusive, pharmacologic therapy initiates with Calcium Channel Blockers (CCB), namely amlodipine or nifedipine $[1,2]$. Whether blood pressure cannot be controlled, labetalol or beta-blocking drug can be added [8]. If hypertension remains difficult to control on both CCB and betablocker and if there is enough certainty of non-presence of renal artery stenosis, angiotensin-converting enzyme inhibitors or angiotensin-receptor blockers may be introduced with careful monitoring of renal function [1]. Other medications include diuretics, minoxidil or clonidine [1]. In patients identified with renovascular cause, corrective therapies such as surgical repair or percutaneus transluminal angioplasty can be performed; however the results are poor with persistent or recurrent HTN [1].

\section{Conclusion}

The patients with WBS have high risk of sudden death and for HTN, thus a multidisciplinary approach to patient is needed with cooperation and interaction between nephrologists and cardiologists.

\section{References}

1. Wayne W, Teresa L (2020) Williams Syndrome. Link: https://bit.ly/3o2lydt
2. Bouchireb K, Boyer O, Bonnet D, Brunelle F, Decramer S, et al. (2010) Clinical features and management of arterial hypertension in children with Williams-Beuren syndrome. Nephrol Dial Transplant 25: 434-438. Link: https://bit.ly/2KzFib8

3. Morris CA, Braddock SR (2020) Health care supervision for children with Williams syndrome. Pediatrics 145: e20193761. Link: https://bit.ly/3I4sVjT

4. Morris CA, Braddock SR (2020) Health care supervision for children with Williams syndrome. Pediatrics 145: e20193761. Link: https://bit.ly/2J22YVu

5. National high blood pressure education program working group on high blood pressure in children and adolescentes. The fourth report on diagnosis, evaluation, and treatmentt of high blood pressure in children and adolescentes. Pediatrics 114: 555-576

6. Kozel AB, Danback JR, Waxler JL, Knutsen RH, de Las Fuentes L, et al. (2014) Williams syndrome predispose to vascular stiffness modified by antihipertensive use and copy number changes in NCF1. Hypertension 63: 7479. Link: https://bit.ly/375V0T4

7. Pober BR, Johnson M, Urban Z (2008) Mechanims and treatment of cardiovascular disease in Williams-Beuren syndrome. J Clin Invest 118: 16061615. Link: https://bit.ly/3655vGV

8. National high blood pressure education program working group on high blood pressure in children and adolescentes. The fourth report on diagnosis, evaluation, and treatmentt of high blood pressure in children and adolescentes. Pediatrics 114: 555-576

Discover a bigger Impact and Visibility of your article publication with

Peertechz Publications

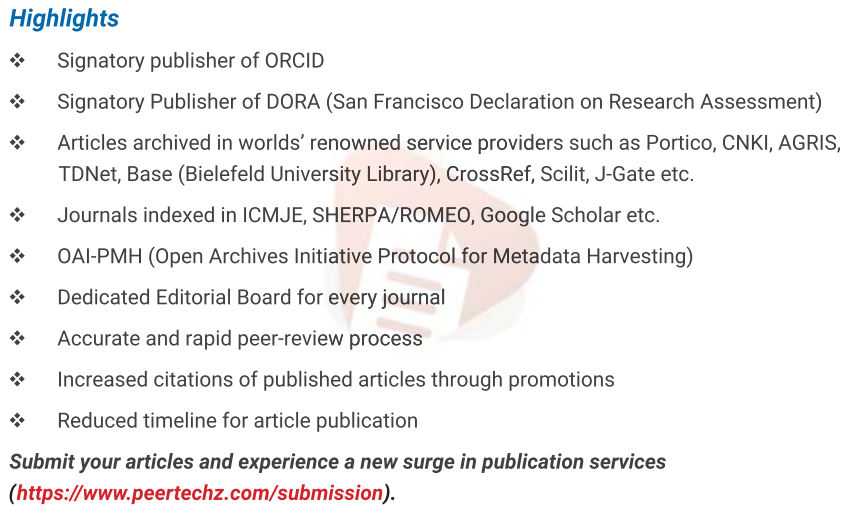

Copyright: @ 2020 Marta N, et al. This is an open-access article distributed under the terms of the Creative Commons Attribution License, which permits unrestricted use, distribution, and reproduction in any medium, provided the original author and source are credited. 